\title{
Kalsiyum Oksalat Kristalizasyonunun Engellenmesi Üzerine Nar (Punica granatum L) Suyunun Etkisi: Bir Optimizasyon Çalışması
}

\author{
Muhammed Bora AKIN*, Hasan ÖKMEN, Seval ALKAN, Hülya TÜRKOĞLU \\ Çankırı Karatekin Üniversitesi, Kimya Mühendisliği Bölümü, Çankırı \\ (ORCID: 0000-0003-3841-1633) (ORCID: 0000-0002-2297-3386) \\ (ORCID: 0000-0001-6420-2697) (ORCID: 0000-0003-0136-663X)
}

\begin{abstract}
$\ddot{O} z$
Ürolitiyazis, idrar yollarının herhangi bir bölümünde taş oluşması veya taş bulunması durumu olarak açıklanmaktadır. İdrar taşlarının sık sık tekrarlandığı bilinmektedir ve tıbbi tedavideki ilerlemelere rağmen, bu durumun tedavisinde sonuç veren bir ilaç tedavisi bulunmamaktadır. Böbrek taşları çeşitli organik ve inorganik bileşiklerden oluşur. Kalsiyum oksalat monohidrat, (COM), böbrek taşlarının ana bileşenidir. Bununla birlikte, böbrek taşlarının oluşum mekanizmaları iyi anlaşılmamıştır. Bu bağlamda, çekirdeklenme, kristal büyümesi ve oluşan COM kristallerinin bir araya gelmesi gibi birkaç varsayım vardır. Bu nedenle çalışmalar yürütülürken doğal ve sentetik katkı maddelerinin kalsiyum oksalat $\left(\mathrm{CaC}_{2} \mathrm{O}_{4}\right)$ kristalizasyonu üzerine etkilerinin araştırılması şeklinde pek çok çalışma ile karşılaşılmaktadır. Bu çalışmada nar suyunun $\mathrm{CaC}_{2} \mathrm{O}_{4}$ kristalizasyonu üzerine engelleme etkisi araştırılmıştır. Laboratuvar ortamında belirlenmiş faktörler 1 şı ğında $\mathrm{CaC}_{2} \mathrm{O}_{4}$ kristalizasyon sürecinin nar suyu tarafından engellenmesi Taguchi ortogonal deneysel tasarımı uygulanarak araştırılmıştır. Çalışmalar sonucunda nar suyunun $\mathrm{CaC}_{2} \mathrm{O}_{4}$ kristalizasyonu üzerine yavaşlatma ve geciktirme etkisi olduğu görülmektedir.
\end{abstract}

Anahtar kelimeler: Kristalizasyon, Engelleme, Katkı maddesi, Nar

\section{Effect of Pomegranate (Punica granatum L) Juice on Inhibition of Calcium Oxalate Crystallization: An Optimization Study}

\begin{abstract}
Urolithiasis is defined as the occurrence of stone or being found stone in any part of the urinary tract. It is known that urine stones are frequently repeated and, despite advances in medical treatment, there is no drug treatment that results in the treatment of this condition. Kidney stones are composed of various organic and inorganic compounds. Calcium oxalate monohydrate (COM) is the main component of kidney stones. However, the mechanisms of the formation of kidney stones are not well understood. In this case, there are some assumptions such as nucleation, crystal growth and the aggregation of formed COM crystals. In this study, the inhibitory effect of pomegranate juice on calcium oxalate $\left(\mathrm{CaC}_{2} \mathrm{O}_{4}\right)$ crystallization was investigated. In the light of the factors determined in the laboratory, using Taguchi orthogonal experimental design on inhibition of $\mathrm{CaC}_{2} \mathrm{O}_{4}$ crystallization process in the presence pomegranate juice was investigated. As a result of study, pomegranate juice has a slowing and inhibition effect on $\mathrm{CaC}_{2} \mathrm{O}_{4}$ crystallization.
\end{abstract}

Keywords: Crystallization, Inhibition, Additive, Pomegranate.

\section{Giriş}

Böbrek taşı günümüze kadar devam edip önemini koruyan yaygın bir hastalıktır. Çünkü kesin bir ilaç tedavisi mümkün değildir ve cerrahi müdahale ile ortadan kaldırılsa da tekrarlama olasıllı̆ı bulunmaktadır. Bu nedenle böbrek taşı oluşumuna ait alternatif çözüm önerileri geliştirilmektedir. Böbrek taşlarının oluşumunda kalsiyum oksalat öne çıkan bileşik olup bu malzemenin kristallenmesi ardından büyümesiyle kalsiyum oksalat monohidrat (COM) ve kalsiyum oksalat dihidrat (COD) türevli böbrek taşları oluşmaktadır [1-2].

\footnotetext{
*Sorumlu yazar: mbakin@ karatekin.edu.tr

Geliş Tarihi: 04.03.2019, Kabul Tarihi: 01.07.2019
} 
Pek çok etken kristalizasyon prosesini etkilemektedir. Sıcaklık, pH, aşırı doygunluk, karıştırma, safsızlıklar ve katkı maddeleri başlıca etkenler olarak sayılabilir. Bunların içinde kristalizasyonu en çok etkileyen katkı maddeleridir. Çekirdek oluşumu, kristal büyümesi ve kristal morfolojisi ile boyutu katkı maddeleri sayesinde kolayca değiştirilebilmektedir [3]. Ürün kalitesi ve kristalizasyon parametrelerini etkilemek için katkı maddeleri kullanılmaktadır [4]. Biyomineralizasyon sayesinde organik doku matrisi inorganik kristalleri kontrol etmektedir. Bu kontrol, kristalin çözeltide büyümesi esnasında kullanılan bazı maddelerin kristal yüzeylerine bağlanması ve kristal büyümesini engellemesiyle oluşmaktadır. Bir grubu kristal yüzeyinde ve diğer grubu çözelti içinde bulunan bu moleküller sayesinde kristali oluşturan fazın özelliklerinin etkilenebileceği düşünülmektedir [5]. Yapılan çalışmalarda polimerlerin katkı olarak kullanılmaları yeni polimerlerin üretilmesi ve bunların engelleme etkisinin incelenmesi yolunu açmıştır. Özellikle buharlaştırıcılar ve kazanlarda 1sı transferine engel teşkil eden kabuk oluşumunun önüne geçmek için bir seçenek oluşturmaktadırlar [6]. Diğer yandan insan vücudunda oluşan taşları önlemeye yönelik olarak biyopolimer sentezleme yöntemleri denenirken doğada bulunan çeşitli kaynaklardan ekstraksiyon vb. süreçlerle ele geçirilen maddeler de kristalizasyonu engelleme amaciyla kullanılmaktadır. Bu çalışmalardan birinde karahindiba ekstraktının kristalizasyona etkisi incelenmiş ve olumlu sonuçlar elde edilmiştir [7]. Yapılan çalışmalarda sentetik ve doğal katkı maddelerinin üretilmesi ve bunların engelleme etkisinin incelenmesi yolunu açmıştır.

Nar, 1lıman iklimlerde yetişen bir meyve türüdür. Punicaceae ailesinden olan bu meyve, gövdesini oluşturan yüzlerce tanecikten oluşmuştur ve taneciklerin herbirinde küçük çekirdekler bulunmaktadır. Tadı yöreye ve toprak yapısıyla bağlantılı olarak bazen hafif ekşi ve bazen de tatlı olabilmektedir.

Meyvenin yenilebilir kısmı "sarcotesta" olarak isimlendirilir ve bu yenilebilir kısım, narın toplam ağırlığının \%52'sini meydana getirir. $100 \mathrm{~g}$ nar tanesinde; $79 \mathrm{~g}$ su, 16,7 g karbonhidrat, $0,7 \mathrm{~g}$ protein ve $0,6 \mathrm{~g}$ yağ olduğu ve $78 \mathrm{kcal}$ enerji verdiği bildirilmektedir [8-9]. Nar suyunun kimyasal bileşimi incelendiğinde genetik ve ekolojik faktörlerle bazı değişikliklerin olduğu görülür. $\mathrm{Bu}$ faktörlerin yanısıra, nar suyu üretim şartları da kimyasal bileşimi etkiler. Kimyasal bileşim değerleri için endüstriyel şartların uygulandığı çok sayıdaki nar suyu analizlerinin kullanımı bir yaklaşım olarak kabul edilmektedir [10-12]. Nar suyu vitamince oldukça zengin bir karışım içerir. Bu vitaminlerin başında gelen askorbik asit, bazı nar suyu içeriklerinde ortalama $135,8 \mathrm{mg} / \mathrm{L}$ olurken başka içeriklerde $7 \mathrm{mg} / \mathrm{L}$ gibi düşük düzeylerde de görülebilmektedir. Nar suyu, vitamin B açısından da zengindir. Nar suyunun $5,73 \mathrm{mg} / \mathrm{L}$ riboflavin ve $48,5 \mathrm{mg} / \mathrm{L}$ tiamin içerdiği bir çalışmada bildirilmektedir. Aynı bölgede yetiştirilen farklı beş nar çeşidi incelendiğinde, narın $C$ vitamini içeriğii, çekirdekli taze ağırlık göz önüne alındığında 52,8-72,0 mg/100 g arasında; kabuk göz önüne alındığında ise 76,8-118,4 mg/100 g arasında değişmektedir [12]. Nar incelendiğinde laktik, tartarik, fumarik, malik ve sitrik asit başlica organik asitler olarak sıralanabilir. Narın yenilebilir kısmını oluşturan tohumların zarlarında sitrik asit diğerlerine nazaran baskındır ve sitrik asit titrasyon asitliğinin kaynağıdır [13]. Sitrik asit miktarının değişimi, narın olgunlaşma durumu ve yetiştiği çevresel şartlara bağlıdır [14]. Çeşitler arasında asit içeriği farklılığının yüksek olması ve bulunan asit miktarlarının da geniş sınırlar arasında değişmesi nedeniyle narların sınıflandırılması yapılırken tat duyusuna dayalı olarak tatlı, ekşi, mayhoş ifadelerinin kullanılması seçilmiştir [12]. Olgunlaşma sırasında aşamalı bir şekilde asitliğin düşmesi ile toplam şeker miktarının artması söz konusudur ve bu doğal bir durumdur. Bu durum narın tat ve kokusunu sağlayan en önemli olgu olarak karşımıza çıkarken, diğer yandan asitlikteki bu değişim antosiyanin pigmentlerinin renginin değişimini de getirmektedir [15].

Kalsiyum oksalat kristalizasyonuna çeşitli nar suyunun etkisi bu çalışma kapsamında sıcaklık, nar suyu miktarı ve nar suyu türü parametre olarak seçilerek engelleme etkisi, kristalizasyon hızının değişimi ve gecikme zamanı incelenmek üzere iki cevaplı Taguchi $L_{9}$ ortogonal deneysel tasarımı kullanılmıştır.

\section{Materyal ve Metot}

$\mathrm{CaC}_{2} \mathrm{O}_{4}$ 'ün elde edildiği deneylerde kullanılan kalsiyum klorür $\left(\mathrm{CaCl}_{2} \cdot 2 \mathrm{H}_{2} \mathrm{O}\right)$ ve sodyum oksalat $\left(\mathrm{Na}_{2} \mathrm{C}_{2} \mathrm{O}_{4}\right)$ Sigma Aldrich'ten temin edilmiştir. Taze olarak sağlanan nar tanelerinden ayrılmış, ayrılan taneler elle sıkılarak suyu biriktirilmiştir. Daha sonra süzülerek kabuk ve diğer kısımlardan gelmesi muhtemel katı parçacıkların ayrılması sağlanmıştır. Elde edilen nar suyu bekletilmeden kristalizasyon deneylerinde kullanılırken, ayrılan bir miktar nar suyu da bir hafta sonra kristalizasyon deneylerinde 
kullanılmıştır. Bu işlemlerle kullanılan nar suyu dışında ticari olarak satılan nar suyu da kristalizasyon deneylerinde katkı maddesi olarak kullanılmıştır.

Kristalizasyon deneyleri eş molaritede $\mathrm{CaCl}_{2}$ ve $\mathrm{Na}_{2} \mathrm{C}_{2} \mathrm{O}_{4}$ çözeltilerinin karıştırılması ile başlatılırken deneylerde kullanılan $1 \mathrm{~L}$ hacimli çift cidarlı cam reaktörün 1sısının sabit tutulması için otomatik sıcaklık kontrollü su banyosu kullanılmıştır. Tüm deneylerde başlangıç konsantrasyonu 7,0.10${ }^{4} \mathrm{M}$ olan $\mathrm{CaCl}_{2}$ ve $\mathrm{Na}_{2} \mathrm{C}_{2} \mathrm{O}_{4}$ çözeltileri kullanılarak $\mathrm{CaC}_{2} \mathrm{O}_{4}$ konsantrasyonunun $3,5.10^{-4} \mathrm{M}$ olmas1 sağlanırken, deney boyunca karıştırma bir manyetik karıştırıcı ile sağlanmıştır. $90 \mathrm{dk}$ süren deneyler sonunda reaktör ortamının sıcaklık ve iletkenlik değerleri bir multimetre (WTW inoLab® Multi 9420 IDS) vasıtasıyla bilgisayara aktarılmıştır. Elde edilen iletkenlik değerleri zamana karşı grafik haline getirildikten sonra kristalizasyonun gecikme süreleri ve katkı kullanılmaksızın yapılan deneylerle kıyaslanarak yavaşlama etkileri bulunmuş ve bu sayede deneylerdeki parametrelerin kristalizasyonu engelleme etkisi ortaya çıkarılmıştır.

Deneylerde sicaklık $\left(30,33,5\right.$ ve $\left.37^{\circ} \mathrm{C}\right)$, katkı miktarı $(25,50$ ve $75 \mathrm{~mL})$ ve nar suyu tipi (tanelerden sıkılmış hemen kullanılmış, tanelerden sıkılmış bir hafta bekletilerek kullanılmış ve ticari nar suyu) faktörler olarak kullanılmıştır (Tablo 1). Buzdolabında bir hafta süre ile $4{ }^{\circ} \mathrm{C}$ 'de bekletilen ürünün bu süre içinde dibe çöken kısmı deneylerde kullanılmamıştır. Ticari ürün kullanımında her deney öncesi elle çalkanarak paket açılmış ve daha sonra deneyde kullanılmıştır.

Tablo 1. Taguchi deneysel tasarım modelinde kullanılan parametreler ve seviyeleri

\begin{tabular}{|c|c|c|c|}
\hline Faktörler & Sicaklık $\left(^{\circ} \mathbf{C}\right)$ & Miktar $(\mathbf{m L})$ & Nar suyu tipi \\
\hline Seviye 1 & 30 & 25 & Tanelerden sıkılmış hemen kullanılmış \\
\hline Seviye 2 & 33,5 & 50 & Tanelerden sıkılmış bir hafta bekletilmiş \\
\hline Seviye 3 & 37 & 75 & Ticari \\
\hline
\end{tabular}

Taguchi deneysel tasarımıyla yapılan bu çalışmada elde edilen cevaplar iletkenlik değerlerinin oluşturduğu eğrilerle sağlanmaktadır: Kristalizasyon hızı ve gecikme zamanı. Gecikme zamanı, aşırı doygunluk oluşumu ve kristallerin görünmesi arasındaki zaman olarak tanımlanmaktadır ve çekirdeklenme hızının bir ölçüsüdür [3]. Kristalizasyon hızı ile ilgili yorum yapılabilmesi için çalışmanın başında üç ayrı sıcaklık için katkısız kontrol deneyleri yapılmıştır. Bu sıcaklıklarda iletkenlik değerleri zamana karşı grafik haline getirildiğinde, birbirlerinden farklı eğimler oluşturmaktadır. Kristalizasyon boyunca, ortamda bulunan $\mathrm{Ca}^{2+}$ ve $\mathrm{C}_{2} \mathrm{O}_{4}^{2-}$ iyonlarının reaksiyona girmesiyle $\mathrm{kat}_{1} \mathrm{CaC}_{2} \mathrm{O}_{4}$ oluşarak çökmekte ve böylece zamanla azalan iyonik kuvvet sayesinde iletkenlik zamanla azalmaktadır. $\mathrm{Bu}$ durumdan hareketle kristalizasyon takip edilebilmektedir. Başlangıç zamanlarında eğimlerin elde edilmesiyle hızlı gerçekleşen kristalizasyon prosesinde yüksek bir eğim görülürken, hızın düştüğü ya da kristalizasyonun hiç gerçekleşmediği durumlarda iletkenlik değerinin zamanla oluşturacağı eğrinin eğimi daha düşük bir değer vermektedir. Katkısız deneylerde gerçekleşen kristalizasyon sürecinde zamana karşı iletkenlik değerleri grafiğe geçirilmiş ve eğim değerleri $\left(\mathrm{k}_{0}\right)$ elde edilmiştir. Aynı işlem katkı olarak kullanılan nar suları varlığında tekrar edilmiş ve eğim değerleri $\left(\mathrm{k}_{\mathrm{i}}\right)$ elde edilmiştir. Katkısız deneylerde elde edilen eğimler $\left(\mathrm{k}_{0}\right)$ ve katk1 varlı̆̆ında elde edilen deneylerde elde edilen eğimler $\left(\mathrm{k}_{\mathrm{i}}\right)$ oranlanarak $\left(\mathrm{k}_{0} / \mathrm{k}_{\mathrm{i}}\right)$ elde edilen değerler yavaşlamanın bir ölçüsü olarak cevap olarak deneysel tasarımda kullanılmıştır. Ancak, bazı deneylerde iletkenliğin değişmediği ve kristalizasyonun gerçekleşmediği görüldüğ̈̈nden $\mathrm{CaC}_{2} \mathrm{O}_{4}$ büyümesini engelleyici olarak etkinin ortaya çıkarılmasında gecikme zamanı da kullanılmıştır. Tablo 2'de görülebileceği gibi Taguchi $\mathrm{L}_{9}$ ortogonal deney tasarımı için, üç seviyeli üç parametreli dokuz deney oluşturulmuştur. Taguchi deney tasarımında en iyi sonuç için çalışma yapılmıştır. En iyi sonuç hem $\mathrm{k}_{0} / \mathrm{k}_{\mathrm{i}}$ değerinin hem de gecikme zamanına ait cevaplarda en yüksek sayısal değerin bulunmasıyla oluşmaktadır.

Elde edilen cevaplar MiniTab programı kullanılarak oluşturulan Taguchi deneysel tasarımına yerleştirilmiş ve elde edilen etki değerlendirmesi çizimi ve ortalamalar için cevap tablosundan sonuçların yorumlanmasında yararlanılmışır. 
Tablo 2. Taguchi L9 ortogonal deneysel tasarım modeli

\begin{tabular}{|c|c|c|c|}
\hline \multirow{3}{*}{ Seviye } & \multicolumn{3}{|c|}{ Kristalizasyon Geciktirme Parametre Seviyesi } \\
\hline & $\mathbf{A}$ & B & C \\
\hline & Sicaklık $\left({ }^{\circ} \mathrm{C}\right)$ & Miktar (mL) & Nar suyu tipi \\
\hline 1 & 30 & 25 & Tanelerden sıkılmış hemen kullanılmış \\
\hline 2 & 30 & 50 & $\begin{array}{c}\text { Tanelerden s1kılmış bir hafta } \\
\text { bekletilmiş }\end{array}$ \\
\hline 3 & 30 & 75 & Ticari \\
\hline 4 & 33,5 & 75 & $\begin{array}{l}\text { Tanelerden s1k1lmış bir hafta } \\
\text { bekletilmiş }\end{array}$ \\
\hline 5 & 33,5 & 25 & Ticari \\
\hline 6 & 33,5 & 50 & Tanelerden sıkılmış hemen kullanılmış \\
\hline 7 & 37 & 50 & Ticari \\
\hline 8 & 37 & 75 & Tanelerden sıkılmış hemen kullanılmış \\
\hline 9 & 37 & 25 & $\begin{array}{c}\text { Tanelerden s1kılmış bir hafta } \\
\text { bekletilmiş }\end{array}$ \\
\hline
\end{tabular}

\section{Bulgular ve Tartışma}

Tasarıma göre yapılan deneyler sonucunda $\mathrm{k}_{0} / \mathrm{k}_{\mathrm{i}}$ değerleri ve gecikme süreleri elde edilmiştir. Elde cevaplar Tablo 3'te verilmektedir. Çalışmada elde edilen değerlerin analizinde MiniTab programı kullanıldığında Tablo 4'te ve Tablo5'te verilen her iki cevap için verilen ortalamalar için cevap tabloları program tarafindan oluşturulmaktadır.

Tablo 3. Deneyler sonucunda elde edilen cevaplar

\begin{tabular}{|c|c|c|c|c|c|}
\hline Deney & $\begin{array}{c}\text { Sıcaklık } \\
\left({ }^{\circ} \mathbf{C}\right)\end{array}$ & $\begin{array}{c}\text { Miktar } \\
(\mathbf{m L})\end{array}$ & Nar suyu tipi & ko/k, & $\begin{array}{c}\text { Gecikme } \\
\text { Süresi, } \\
\mathbf{T}_{\text {ind }}(\mathbf{d k})\end{array}$ \\
\hline $\mathbf{1}$ & 30 & 25 & Tanelerden sıkılmış hemen kullanılmış & 4,23 & 3,34 \\
\hline $\mathbf{2}$ & 30 & 50 & Tanelerden sıkılmış bir hafta bekletilmiş & 103,75 & 52,83 \\
\hline $\mathbf{3}$ & 30 & 75 & Ticari & 393,78 & 90 \\
\hline $\mathbf{4}$ & 33,5 & 75 & Tanelerden sıkılmış bir hafta bekletilmiş & 244,24 & 79,83 \\
\hline $\mathbf{5}$ & 33,5 & 25 & Ticari & 271,52 & 48 \\
\hline $\mathbf{6}$ & 33,5 & 50 & Tanelerden sıkılmış hemen kullanılmış & 14,6 & 7,83 \\
\hline $\mathbf{7}$ & 37 & 50 & Ticari & 12,18 & 4 \\
\hline $\mathbf{8}$ & 37 & 75 & Tanelerden sıkılmış hemen kullanılmış & 79,91 & 31,84 \\
\hline $\mathbf{9}$ & 37 & 25 & Tanelerden sıkılmıs bir hafta bekletilmiş & 640,04 & 90 \\
\hline
\end{tabular}

Tablo 4'deki durum incelendiğinde C2B3A3 sıralamasının en iyi gecikme süresinin oluşturulmasında kullanılabileceği görülmektedir. Bu sonuç üzerine yapılan kontrol denemesinde hedeflenen $90 \mathrm{dk}$ gecikme süresi elde edilmiştir.

Tablo 4. $\mathrm{k}_{0} / \mathrm{k}_{\mathrm{i}}$ kullanılarak oluşturulan ortalamalar için cevap tablosu

\begin{tabular}{|c|c|c|c|}
\hline Level & A & B & C \\
\hline 1 & 167,25 & 86,88 & 32,91 \\
\hline 2 & 176,79 & 151,73 & 329,34 \\
\hline 3 & 244,04 & 349,47 & 225,83 \\
\hline Delta & 76,79 & 262,59 & 296,43 \\
\hline Rank & 3 & 2 & 1 \\
\hline
\end{tabular}

Şekil 1'de MiniTab programı tarafindan Tablo 4'de elde edilen tablo ortalamaların ana etki çizimi şeklinde verilmektedir. 


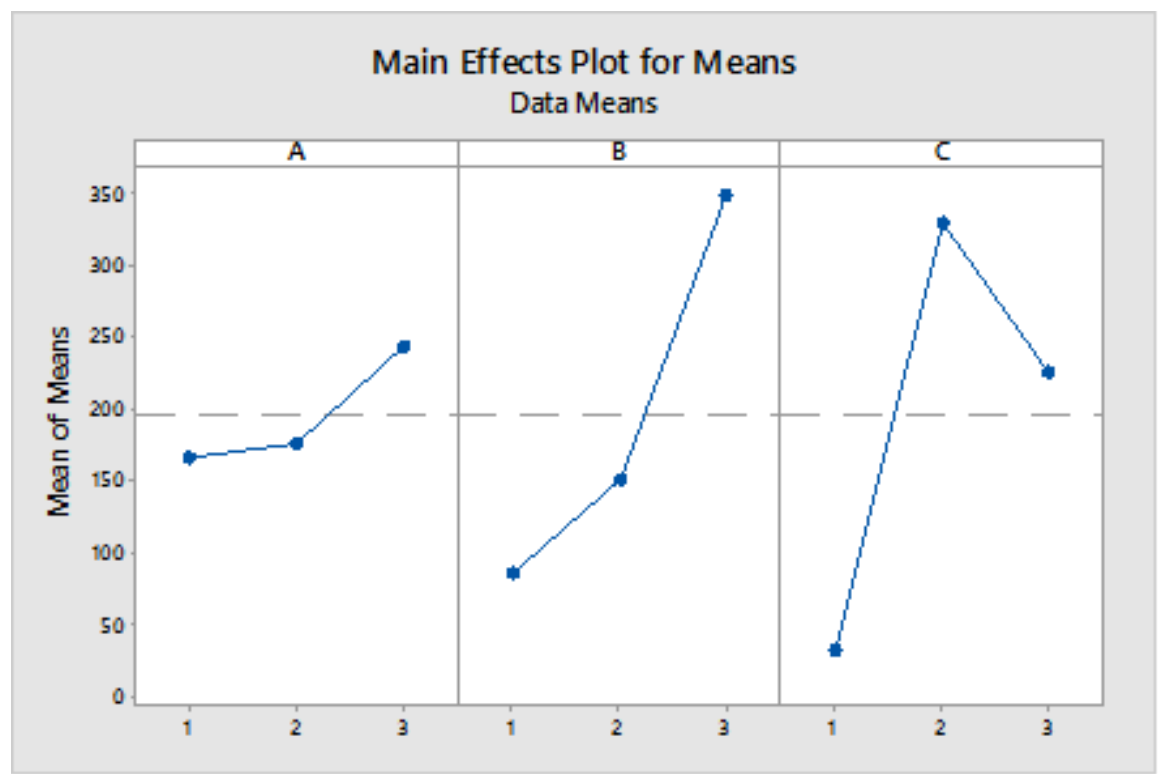

Şekil 1. $\mathrm{k}_{0} / \mathrm{k}_{\mathrm{i}}$ kullanılarak oluşturulan ortalamaların ana etki çizimi

Tablo 5'deki durum incelendiğinde C2B3A1 sıralamasının en iyi gecikme süresinin oluşturulmasında kullanılabileceği görülmektedir. $\mathrm{Bu}$ sonuç üzerine yapılan kontrol denemesinde hedeflenen $90 \mathrm{dk}$ gecikme süresi elde edilmiştir.

Tablo 5. Gecikme zamanı kullanılarak oluşturulan ortalamalar için cevap tablosu

\begin{tabular}{|c|c|c|c|}
\hline Level & A & B & C \\
\hline 1 & 48.72 & 29.06 & 14.34 \\
\hline 2 & 45.22 & 44.22 & 74.22 \\
\hline 3 & 41.95 & 62.61 & 47.33 \\
\hline Delta & 6.78 & 33.55 & 59.88 \\
\hline Rank & 3 & 2 & 1 \\
\hline
\end{tabular}

Şekil 2'de MiniTab programı tarafından Tablo 4'deki durum ortalamaların ana etki çizimi şeklinde verilmektedir.

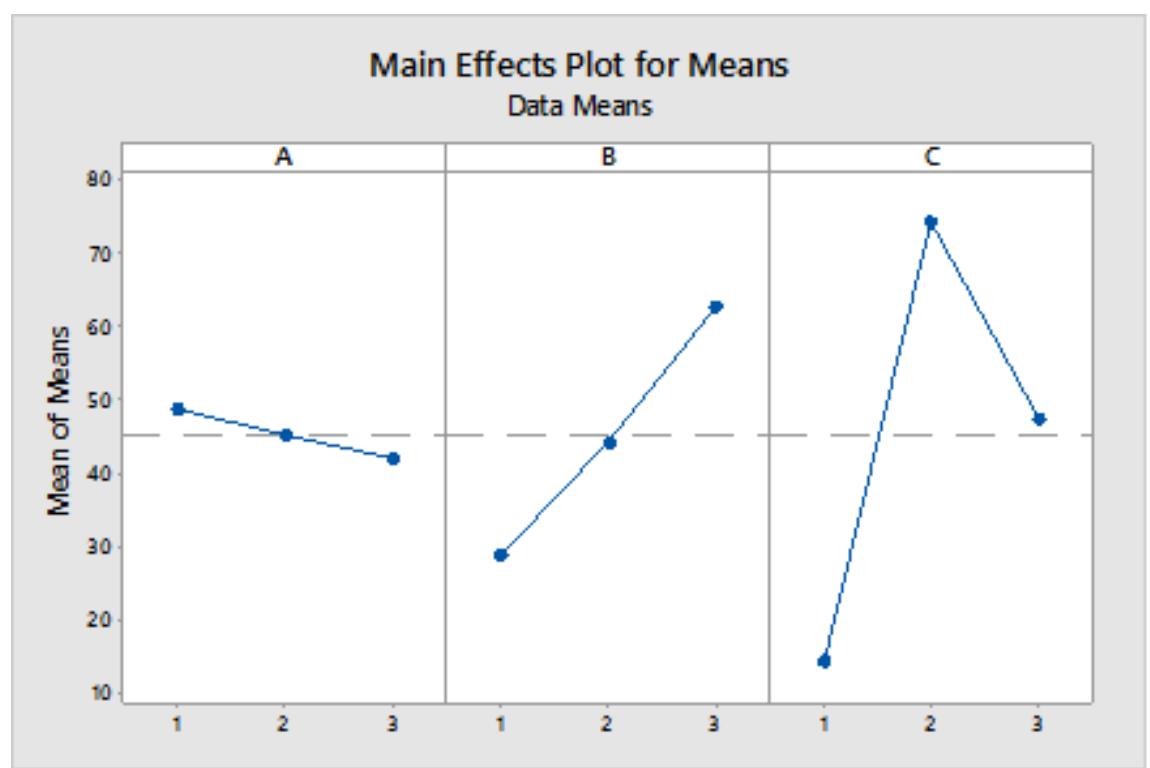

Şekil 2. Gecikme zamanları kullanılarak oluşturulan ortalamaların ana etki çizimi 


\section{Sonuç ve Öneriler}

$\mathrm{CaC}_{2} \mathrm{O}_{4}$ kristalizasyonun engellenmesinde nar suyunun çeşidi fark etmeksizin etkili bir katkı olduğu görülmüştür. Sonuçlar nar suyunun kalsiyum oksalat kristalizasyonun yavaşladığını ve engellendiğini göstermektedir.

Çalışmada Taguchi L9 ortogonal dizisi, performansın birçok faktöre bağlı olduğu ürün ve işlemlerin kalitesini artırmak amacıyla tasarlanmıştır. Bu çalışmada sıcaklık, nar suyu miktarı ve nar suyu tipi dikkate alındığında kristalizasyonun yavaşlaması ve gecikme süresi üzerinde en etkili faktörün nar suyu tipi olduğu görülmüştür. İkinci etkili parametre ise nar suyu miktarı olarak bulunmuştur. Sıcaklık bu iki parametre ile kıyaslandığında en az etkili parametre olarak ortaya çıkmaktadır. Kristalizasyonun en yavaş gerçekleşeceği parametre kombinasyonu, $75 \mathrm{~mL}$ taze sıkıldıktan sonra bir hafta bekletilen nar suyunun $37^{\circ} \mathrm{C}$ sıcaklıkta gerçekleştirilen kristalizasyon deneyinde kullanımı ile elde edilmiştir.

\section{Kaynaklar}

[1] El-Shall H., Jeon JH., Abdel-Aal E.A., Khan S., Gower. L., Rabinovich Y. 2004. A Study of Primary Nucleation of Calcium Oxalate Monohydrate: II. Effect of Urinary Species, Cryst. Res. Technol. 39(7): 577-585.

[2] Atuğ F., Canoruç N. 2006. Tekrarlayan Üriner Sistem Kalsiyum Taşlarının Metabolik Değerlendirmesi ve Medikal Yaklaşımlar, Dicle Tıp Dergisi 33(1): 48-52.

[3] Jones, A.G. 2002. Crystallization Process Systems, Butterwart tleinemann, London UK.

[4] Sarig S., Kahana F., Leshe, R. 1975. Selection of Threshold Agents for Calcium Sulfate Scale Control on the Basis of Chemical Structure, Desalination,17, 215-229.

[5] Westbroek P., de Jong E.W. 1983. Biominerallization and Biological Metal Accumulation, Reidel, Dordrecht, Holland.

[6] Akyol E., Öner M. 2007. The Effect of Polyelectrolytes on Calcium Oxalate Crystallization, Journal of Engineering and Natural Sciences - Sigma Mühendislik ve Fen Bilimleri Dergisi 25(1): 48-57.

[7] Akyol E. 2016. Kalsiyum Oksalat Monohidrat Kristal Büyümesine Karahindiba (Taraxacum Officinale) Bitkisinin Etkisinin İncelenmesi, Iğdır Üniversitesi Fen Bilimleri Enst. Der./Iğdır Univ. J. Inst. Sci. \& Tech., 6 (3): 97-105.

[8] Kulkarni A.P., Aradhya S.M. 2005. Chemical Changes and Antioxidant Activity in Pomegranate Arils During Fruit Development. Food Chemistry, 93 (2): 319-324.

[9] Hernadez F., Melgarejo P., Tomas-Barberan F.A., Artes F. 1999. Evolution of Juice Anthocyanins During Ripening of New Selected Pomegranate (Punica granatum) Clones, Eur. Food Res. Technol. 210: 39-42.

[10] Bayındırlı L., Şahin S., ve Artık N. 1994. The Effects of Clarification Methods of Pomegranate Juice Quality. Fruit Processing, 94 (9): 267-270.

[11] Alper N. 2001. Nar Suyu Üretimi Üzerine Araştırmalar, Hacettepe Üniversitesi Fen Bilimleri Enstitüsü. Doktora Tezi, Ankara.

[12] Karaca E. 2011. Nar Suyu Konsantresi Üretiminde Uygulanan Bazı İşlemlerin Fenolik Bileşenler Üzerine Etkisi. Yüksek Lisans Tezi, Çukurova Üniversitesi Fen Bilimleri Enstitüsü, Adana.

[13] Saxena A.K., Manan J.K., Berry S.K. 1987. Pomegranades; Postharvest Technology, Chemistry and Processing. Indian Food Packer, 41 (4): 43-60.

[14] Cabrita L., Fossen T., Anderson O.M. 2000. Colour and Stability of The Six Common Anthocyanidin 3-glucosides in Aqueous Solutions. Journal of Food Science, 68: 101-107.

[15] Cordenunsi B.R., Nascimento J.R.O., Lajolo F.M. 2003. Physicochemical Changes Related to Quality of Five Strawberry Fruit Cultivars During Cool-Storage. Food Chemistry, 83: 167-173. 